\title{
Transepithelial Transport of Telmisartan in Caco-2 Monolayers
}

\author{
Yoshikazu Goto, ${ }^{a}$ Shirou Itagaki, ${ }^{b}$ Shinichiro UmedA, ${ }^{b}$ Masaki KobaYashi, ${ }^{b}$ Takeshi HiRano, ${ }^{b}$ \\ Ken IsEKI, ${ }^{b}$ and Koji TADANO ${ }^{*, a}$ \\ ${ }^{a}$ Department of Pharmacy, Sapporo City General Hospital; Sapporo 060-8604, Japan: and ${ }^{b}$ Department of Clinical \\ Pharmaceutics \& Therapeutics, Graduate School of Pharmaceutical Sciences, Hokkaido University; Sapporo 060-0812, \\ Japan. Received August 25, 2005; accepted October 2, 2005; published online October 5, 2005
}

\begin{abstract}
Telmisartan is the most recently marketed angiotensin II type 1 receptor antagonist. Drug-drug interactions involving transporters can directly affect the therapeutic safety and efficacy of many important drugs. In clinical practice, telmisartan is coadministered with many kinds of drugs. However, little is known about the contribution of transporters to the intestinal transport of telmisartan. The aim of this study was to determine the transport mechanism of telmisartan across intestinal epithelial cells. In the presence of an inwardly directed proton gradient, the apical-to-basal transport of telmisartan was greater than basal-to-apical transport. Thus, we focused on the uptake mechanism of telmisartan across brush-border membranes. The uptake of telmisartan by Caco-2 cells was shown to be energy- and proton-dependent. Although some monocarboxylates inhibited the uptake of telmisartan, L-lactic acid, which is a typical substrate of the monocarboxylate transporter (MCT) 1MCT4, did not affect the uptake of telmisartan. Preloading of acetic acid enhanced the uptake of telmisartan, showing a trans-stimulation effect. These results suggest that the carrier-mediated transport system is involved in the uptake of telmisartan by Caco-2 cells and that the apical-localized transport system is similar to MCTs, but not MCT1-MCT4. It is possible that telmisartan reduce the absorption of coadministered drugs by sharing the MCTs. Since MCTs have an important role in the intestinal absorption of pharmacologically active compounds, it is important to be aware of the potential of telmisartan-drug interactions involving MCTs and to act in order to prevent undesirable and harmful consequences.
\end{abstract}

Key words telmisartan; monocarboxylate transporter; $\mathrm{AT}_{1}$ receptor antagonist; Caco-2 cell; drug-drug interaction

In recent years, several specific, orally active, nonpeptide angiotensin II type $1\left(\mathrm{AT}_{1}\right)$ receptor antagonist have been widely used by patients with high blood pressure, kidney disease and heart failure. ${ }^{1)}$ Telmisartan (BIBR 277) is the most recently marketed $\mathrm{AT}_{1}$ receptor antagonist. ${ }^{2)}$ Telmisartan lowers blood pressure though blockade of the renin-angiotensin-aldosterone system. ${ }^{3}$ ) The efficacy of telmisartan has been shown to be at least equivalent to that of many other commonly prescribed antihypertensive agents, including enalapril, lisinopril, amlodipine, atenolol and losartan. ${ }^{4-8)}$ Telmisartan has demonstrated a safety profile similar to that of placebo with respect to the incidence of adverse events and abnormalities in standard laboratory tests. ${ }^{3)}$ Furthermore, unlike angiotensin-converting enzyme (ACE) inhibitors, telmisartan has not been associated with cough, a characteristic shared with other members of the class. ${ }^{9-11)}$

Recent studies have shown that multiple transporters are expressed in the gastrointestinal tract and play an important role in the secretion and absorption of pharmacologically active compounds. ${ }^{12-14)}$ It is possible that drug-drug interactions involving transporters directly affect the therapeutic safety and efficacy of many important drugs. ${ }^{12)}$ In clinical practice, telmisartan is coadministered with many kinds of drugs. It has been reported that several cardiovascular drugs, including digoxin, ACE inhibitors and calcium antagonists, interact with intestinal transporters. ${ }^{15-17)}$ However, little is known about the contribution of transporters to the intestinal transport of telmisartan. The human colon adenocarcinoma cell line Caco-2 has been used as a model in which to study intestinal absorption or secretion of various drugs. ${ }^{18)}$ This cell line spontaneously differentiates in culture into polarized cell monolayers with many enterocyte-like properties of transporting epithelia. Caco-2 cells retain various trans- porters expressed in the intestine. Using this model, a number of studies have been performed to characterize the intestinal transport mechanism.

The present study was carried out to elucidate the transport mechanism of telmisartan across intestinal epithelial cells using Caco-2 cells.

\section{MATERIALS AND METHODS}

Chemicals Telmisartan (Micardis ${ }^{\circledR}$ capsules were purchased from a local wholesaler. Telmisartan was extracted from the Micardis ${ }^{\circledR}$ using DMSO. Atrovastatin, bezafibrate and lisinopril were kindly supplied by Sankyo (Tokyo, Japan), Novartis Pharma (Tokyo, Japan), Kissei Pharmaceutical (Nagano, Japan) and Shionogi Co. (Osaka, Japan), respectively. All other reagents were of the highest grade available and used without further purification. Telmisartan was dissolved in DMSO ( $1 \% \mathrm{w} / \mathrm{v}$ final concentration) due to its hydrophobic property and poor solubility in water. The upper limit of telmisartan concentration was $75 \mu \mathrm{M}$.

Cell Culture Caco-2 cells obtained from American Type Culture Collection (Rockville, MD, U.S.A.) were maintained in plastic culture flasks (Falcon, Becton Dickinson and Co., Lincoln Park, NJ, U.S.A.) as described previously with minor modifications. ${ }^{19)}$ These stock cells were subcultivated before reaching confluence. The medium consisted of Dulbecco's Modified Eagle's Medium (Sigma) supplemented with 10\% fetal bovine serum (ICN Biomedicals, Inc., Aurora, OH, U.S.A.), $1 \%$ nonessential amino acid (Gibco), 2 mm L-glutamine (Gibco) and $100 \mathrm{IU} / \mathrm{ml}$ penicillin $-100 \mu \mathrm{g} / \mathrm{ml}$ streptomycin (Sigma). The monolayer cultures were grown in an atmosphere of $5 \% \mathrm{CO}_{2}-95 \% \mathrm{O}_{2}$ at $37^{\circ} \mathrm{C}$. The cells were given fresh growth medium every $2 \mathrm{~d}$. When the Caco- 2 cells had 
reached confluence, they were harvested with $0.25 \mathrm{~mm}$ trypsin and $0.2 \%$ EDTA $\left(0.5-1 \mathrm{~min}\right.$ at $\left.37^{\circ} \mathrm{C}\right)$, resuspended, and seeded into a new flask. For the transport study, Caco-2 cells were seeded on polycarbonate membrane filters $(3 \mu \mathrm{m}$ in pore size, growth area of $1.0 \mathrm{~cm}^{2}$ ) inside Transwell cell culture chambers (Costar, Cambridge, MA, U.S.A.) at a cell density of $4 \times 10^{5}$ cells $/ \mathrm{cm}^{2}$. The medium was renewed every $2 \mathrm{~d}$, and the cells were used at 16 to $21 \mathrm{~d}$ for the transport experiments. Only monolayers exhibiting transepithelial electrical resistance (TEER) values $>300 \Omega \mathrm{cm}^{2}$ were used. For the uptake study, Caco-2 cells were seeded at a cell density of $6 \times 10^{5}$ cells $/ \mathrm{cm}^{2}$ on 24 -well plastic plates (Corning Costar Corp., Cambridge, MA, U.S.A.). The cell monolayers were fed a fresh growth medium every $2 \mathrm{~d}$ and were used at 4 to $6 \mathrm{~d}$ for the uptake experiments.

Transport Experiments Transcellular transport of telmisartan was measured using monolayer cultures grown in Transwell chambers. The incubation medium used for the transport study was Hank's balanced salt solution (HBSS) containing $137 \mathrm{~mm} \mathrm{NaCl}, 5.4 \mathrm{~mm} \mathrm{KCl}, 1.3 \mathrm{mM} \mathrm{CaCl}_{2}, 0.8 \mathrm{~mm}$ $\mathrm{MgCl}_{2}, 0.4 \mathrm{~mm} \mathrm{KH} \mathrm{PO}_{4}, 0.3 \mathrm{~mm} \mathrm{NaH} \mathrm{PO}_{4}, 0.8 \mathrm{~mm} \mathrm{MgSO}$, $25 \mathrm{~mm}$ D-glucose and $10 \mathrm{~mm}$ MES (pH 6.0) or $10 \mathrm{~mm}$ HEPES $(\mathrm{pH}$ 7.4). After removal of the culture medium from both sides of the Transwell chamber, the cell monolayers were preincubated with HBSS-HEPES $(0.5 \mathrm{ml}$ to the apical side and $1.5 \mathrm{ml}$ to the basal side) at $37^{\circ} \mathrm{C}$ for $20 \mathrm{~min}$. After removal of the medium, the medium on either the basal or apical side of the monolayers was replaced with a fresh medium containing $50 \mu \mathrm{M}$ telmisartan, and that on the opposite side was replaced with a fresh medium alone. The monolayers were incubated for up to $120 \mathrm{~min}$ at $37^{\circ} \mathrm{C}$ and gently shaken (100 rpm). Aliquots (each $100 \mu \mathrm{l}$ ) of the incubation medium on the other side were taken at specified times.

Uptake Studies in Caco-2 Cell Monolayers The uptake experiment was performed as described previously. ${ }^{20,21)}$ Telmisartan uptake was measured using monolayer cultures grown in 24-well plastic plates. The incubation medium used for the uptake study was HBSS-MES (pH 5.5, 6.0, 6.5, 7.0) or HBSS-HEPES ( $\mathrm{pH} \mathrm{7.4,8.0)}$. After removal of the growth medium, cells were preincubated at $37^{\circ} \mathrm{C}$ for $20 \mathrm{~min}$ with $0.5 \mathrm{ml}$ of HBSS-HEPES ( $\mathrm{pH} 7.4$ ). After removal of the medium, $0.5 \mathrm{ml}$ of incubation medium containing a substrate was added. The monolayers were incubated for indicated times at $37^{\circ} \mathrm{C}$. Each cell monolayer was washed rapidly twice with an ice-cold incubation medium at the end of the incubation period. The cells were solubilized with $0.2 \mathrm{ml}$ of $1 \mathrm{~N} \mathrm{NaOH}$ and neutralized with $0.2 \mathrm{ml}$ of $1 \mathrm{~N} \mathrm{HCl}$. After vortexing briefly, a part of the mixture $(100 \mu \mathrm{l})$ was transferred to a fresh tube and $200 \mu \mathrm{l}$ of methanol was added. After centrifugation of the mixture $(12000 \times \mathbf{g}$ for $5 \mathrm{~min})$, the concentration of telmisartan in the supernatant was measured.

Analytical Procedures Telmisartan were determined using an HPLC system equipped with a Shimadzu LC-6A pump and SPD-6A UV detector. The column was a CERI Lcolumn $^{\circledR}$ ODS $(4.6 \mathrm{~mm}$ i.d. $\times 150 \mathrm{~mm})$. In the assay for telmisartan, a mobile phase containing $50 \mathrm{~mm}$ citrate $(\mathrm{pH}$ $2.5)$ : acetonitrile $(50: 50, \mathrm{v} / \mathrm{v})$ was used. Column temperature and flow rate were $40{ }^{\circ} \mathrm{C}$ and $1.0 \mathrm{ml} / \mathrm{min}$, respectively. The wavelength for detection of telmisartan was $295 \mathrm{~nm}$. Protein was measured by the method of Lowry et al. with bovine serum albumin as a standard. ${ }^{22)}$ Statistical significance was evaluated using one-way analysis of variance (one-way ANOVA) or unpaired Student's $t$-test. A value of $p<0.05$ was considered significant.

\section{RESULTS}

Transcellular Transport of Telmisartan in Caco-2 Cells The transcellular transport of telmisartan in Caco- 2 cells was investigated. In the presence of an inwardly directed proton gradient, the apical-to-basal transport of telmisartan was greater than the basal-to-apical transport (Fig. 1). The absorption of drugs from the intestine involves the uptake of drugs across brush-border membranes into cells and exit into the blood across basolateral membranes. In the following study, we focused on the uptake mechanism of telmisartan across brush-border membranes.

Energy- and Proton-Dependent Uptake of Telmisartan by Caco-2 Cells We investigated the characteristics of telmisartan uptake into Caco- 2 cells. Since the Caco- 2 cells were grown in wells, basolateral transporters make a minor contribution to the transport of substrates. ${ }^{23}$ ) Figure 2A shows the effect of extracellular $\mathrm{pH}$ on the uptake of telmisartan by Caco- 2 cells. The uptake markedly increased with a decrease in extracellular $\mathrm{pH}$. Figure $2 \mathrm{~B}$ shows the time course of the uptake of telmisartan. The uptake of telmisartan increased linearly over a period of $5 \mathrm{~min}$. The effects of various compounds on the uptake of telmisartan by Caco- 2 cells were examined to determine whether the transport system for telmisartan depends on ATP metabolic energy. As shown in Table 1, 2,4-dinitrophenol (DNP), an uncoupler of oxidative phosphorylation, and carbonyl cyanide 4-(trifluoromethoxy) phenylhydrazone (FCCP), an ionophore, significantly inhibited the uptake of telmisartan. The concentration dependence of the uptake of telmisartan was determined. However, the uptake of telmisartan was not saturated up to $75 \mu \mathrm{M}$ (data not shown).

Effects of Various Drugs on the Uptake of Telmisartan by Caco-2 Cells The effects of various drugs that are clinically coadministrated with telmisartan on the uptake of telmisartan by Caco- 2 cells were determined. Atorvastatin, ketoprofen and salicylic acid, which are reported to be transported by monocarboxylate transporters (MCTs), ${ }^{24-26)}$ sig-

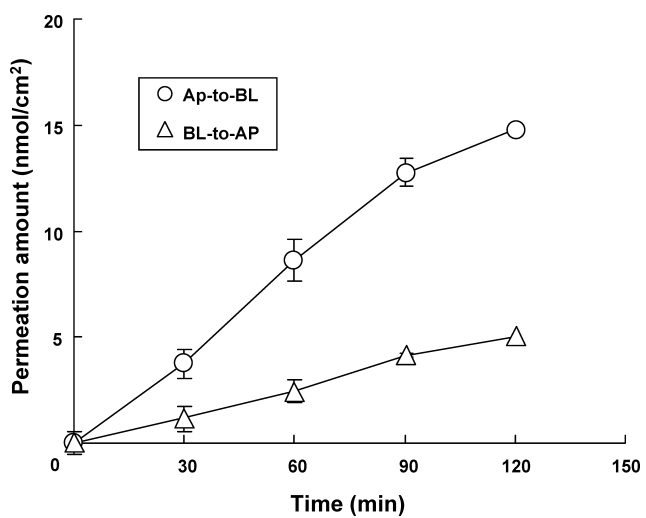

Fig. 1. Time Course of Telmisartan $(50 \mu \mathrm{M})$ Transport across Caco-2 Cell Monolayers

Permeation of telmisartan from the apical side to the basolateral side and that from the basolateral side to the apical side were measured in the presence of proton gradient (apical pH 6.0; basolateral pH 7.4). Each value represents the mean with S.D. of three determinations. 

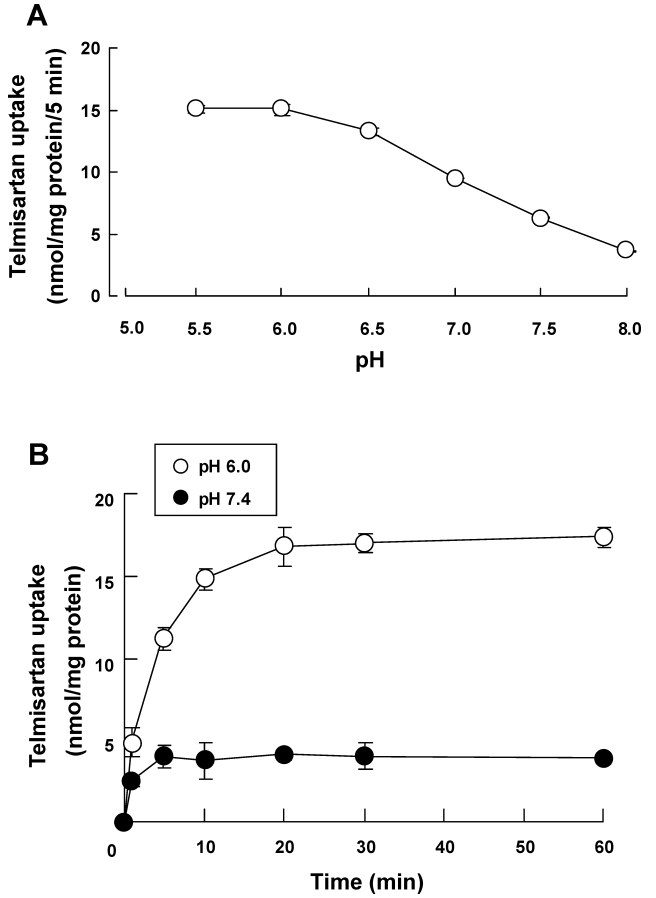

Fig. 2. (A) Effect of Extracellular $\mathrm{pH}$ on the Uptake of Telmisartan by Caco-2 Cells

Cells were incubated in a medium at each $\mathrm{pH}$ containing telmisartan $(50 \mu \mathrm{M})$. (B) Time course of the uptake of telmisartan by Caco- 2 cells. Cells were incubated for indicated periods with telmisartan $(50 \mu \mathrm{M})$.

Table 1. Effects of Metabolic Inhibitors on the Initial Uptake of Telmisartan in Caco-2 Cells

\begin{tabular}{lcc}
\hline \hline Compound & $\begin{array}{c}\text { Concentration } \\
(\mathrm{mM})\end{array}$ & $\begin{array}{c}\text { Telmisartan uptake } \\
(\% \text { of control })\end{array}$ \\
\hline Control & & $100 \pm 5.38$ \\
$\mathrm{DNP}^{a)}$ & 1 & $47.3 \pm 8.17^{* *}$ \\
FCCP & 0.05 & $55.8 \pm 1.43^{* *}$ \\
\hline
\end{tabular}

Cells were incubated in a medium at $\mathrm{pH} 6.0$ containing telmisartan $(50 \mu \mathrm{M})$ for $5 \mathrm{~min}$ with or without (control) inhibitors. a) Cells were preincubated with DNP for $20 \mathrm{~min}$, and then uptake experiments were carried out in the absence of DNP. Each value represents the mean with S.D. of three determinations. The control value for the uptake of telmisartan was $8.30 \pm 0.45 \mathrm{nmol} / \mathrm{mg}$ protein $/ 5 \mathrm{~min}$. $* * p<0.01$, significantly different from the control.

nificantly decreased telmisartan uptake (Table 2).

Effects of Salicylic Acid Derivatives on the Uptake of Telmisartan by Caco-2 Cells In order to clarify whether MCTs are responsible for the uptake of telmisartan by Caco2 cells, the effects of salicylic acid derivatives on the telmisartan uptake were examined. A monocarboxylic acid, acetylsalicylic acid, reduced the uptake of telmisartan (Table 2). On the other hand, salicyl alcohol and salicyl amide did not significantly inhibit telmisartan uptake. A dicarboxylic acid, phthalic acid, did not effect on the uptake of telmisartan.

Effects of Various Monocarboxylates on the Uptake of Telmisartan by Caco-2 Cells In order to characterize the carrier that is responsible for the uptake of telmisartan by Caco-2 cells, the effects of various monocarboxylates on telmisartan uptake were investigated. As shown in Table 2, acetic acid, benzoic acid, butyric acid and propionic acid, as aliphatic and aromatic monocarboxylates, significantly reduced the uptake of telmisartan. However, L-lactic acid,
Table 2. Effects of Various Compounds on the Initial Uptake of Telmisartan in Caco-2 Cells

\begin{tabular}{lcc}
\hline \hline \multicolumn{1}{c}{ Compound } & $\begin{array}{c}\text { Concentration } \\
(\mathrm{mM})\end{array}$ & $\begin{array}{c}\text { Telmisartan uptake } \\
\text { (\% of control) }\end{array}$ \\
\hline Control & & 100 \\
Antilipaemic agents & 0.5 & $72.0 \pm 0.85^{* *}$ \\
$\quad$ Fluvastatin & 0.5 & $84.9 \pm 3.01^{* *}$ \\
Atorvastatin & 0.5 & $92.9 \pm 2.99$ \\
Bezafibrate & & \\
Antihypertensive agents & 1 & $94.0 \pm 3.28$ \\
Enalapril & 1 & $101 \pm 5.45$ \\
Lisinopril & 0.1 & $98.0 \pm 6.87$ \\
Nifedipine & 1 & $99.6 \pm 2.89$ \\
Metoprolol & 1 & $94.2 \pm 6.12$ \\
Furosemide & 1 & $73.5 \pm 1.45^{* *}$ \\
NSAIDs & 5 & $51.0 \pm 5.63^{* *}$ \\
Ketoprofen & & \\
Salicylic acid & 5 & $69.4 \pm 5.42^{* *}$ \\
Salicylic acid derivatives & 5 & $96.1 \pm 3.47$ \\
Acetylsalicylic acid & 5 & $95.2 \pm 7.21$ \\
Salicyl alcohol & 10 & $92.9 \pm 12.8$ \\
Salicyl amide & & $57.8 \pm 1.05^{* *}$ \\
Phthalic acid & 5 & $87.0 \pm 1.03^{*}$ \\
Various monocarboxylates & 5 & $76.4 \pm 4.98^{*}$ \\
Acetic acid & 5 & $64.5 \pm 2.50^{* *}$ \\
Benzoic acid & 5 & $98.0 \pm 6.39$ \\
Butyric acid & 10 & $59.8 \pm 6.21^{* *}$ \\
Propionic acid & 10 & \\
L-Lactic acid & & \\
CHC & & \\
\hline
\end{tabular}

Cells were incubated in a medium at $\mathrm{pH} 6.0$ containing telmisartan $(50 \mu \mathrm{M})$ for $5 \mathrm{~min}$ with or without (control) inhibitors. Each value represents the mean with S.D. of three determinations. The control value for the uptake of telmisartan was $9.36 \pm 0.514$ $\mathrm{nmol} / \mathrm{mg}$ protein $/ 5 \mathrm{~min} . * p<0.05$, $* * p<0.01$, significantly different from the control

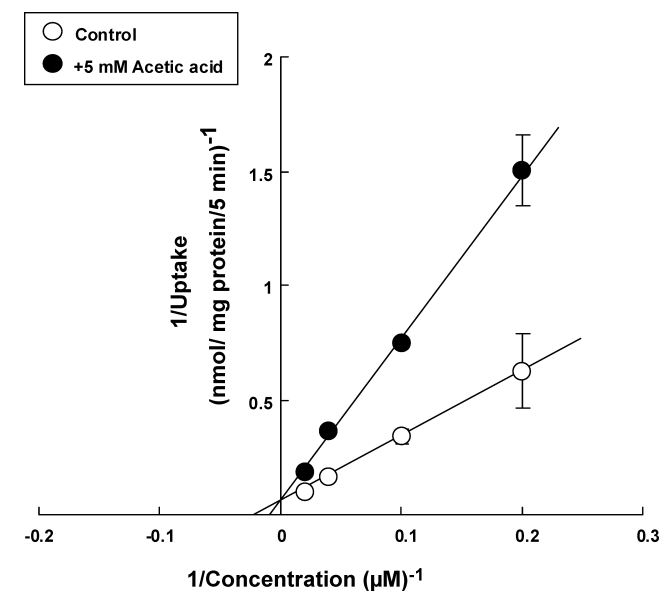

Fig. 3. Lineweaver-Burk Plot for the Uptake of Telmisartan by Caco-2 Cells

Uptake of telmisartan was measured in the presence or absence of $5 \mathrm{~mm}$ acetic acid. Each point represents the mean with S.D. of three determinations.

which is a typical substrate for MCT $1-4,{ }^{27,28)}$ had no effect on telmisartan uptake. The effects of alpha-cyano-4-hydroxycinnamate $(\mathrm{CHC})$, which inhibits the transport of L-lactic acid by MCT 1,2 and $4,{ }^{27,28)}$ were examined. In the presence of $\mathrm{CHC}$, the uptake of telmisartan was significantly decreased.

Figure 3 shows the effects of acetic acid on the uptake of telmisartan in terms of a Lineweaver-Burk plot. Acetic acid was demonstrated to inhibit telmisartan uptake competitively $\left(K_{\mathrm{i}}=2.92 \mathrm{~mm}\right)$. To determine whether the telmisartan trans- 


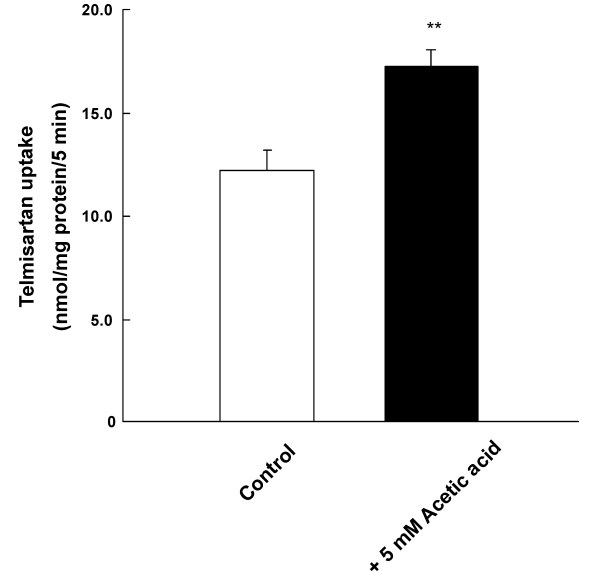

Fig. 4. Trans-Stimulation of Telmisartan Uptake by Preloaded Acetic Acid Caco- 2 cells were preloaded by incubation with $5 \mathrm{~mm}$ acetic acid for $20 \mathrm{~min}(\mathrm{pH} 6.0)$ Acetic acid-preloaded Caco-2 cells were incubated in a medium at $\mathrm{pH} 6.0$ containing telmisartan $(50 \mu \mathrm{M})$ for $5 \mathrm{~min}$. Open and closed columns represent control and preloaded conditions, respectively. Each column represents the mean with S.D. of three determinations. $* * p<0.01$, significantly different from the control.

port system is shared with acetic acid, a trans-stimulation experiment was performed using cells preloaded with acetic acid. As shown in Fig. 4, the uptake of telmisartan was significantly enhanced by preloading with $5 \mathrm{~mm}$ acetic acid.

\section{DISCUSSION}

In clinical practice, changes in pharmacokinetics due to drug-drug interactions can often directly affect the therapeutic safety and efficacy of many important drugs. Traditionally, a change in metabolic clearance of a drug, particularly via cytochrome P450-mediated metabolism, has been considered as the cause of many clinically important drug interactions. ${ }^{29)}$ Now, it is increasingly recognized that changes in the activity of drug transporters may also substantially influence the absorption of administered drugs from the intestine, as well as distribution into various organs and secretion into urine, bile and intestinal lumen. ${ }^{30}$ )

Since telmisartan is the most recently marketed $\mathrm{AT}_{1}$ receptor antagonist, the transport mechanisms of telmisartan in intestinal absorption has not yet been elucidated. In this study, we investigated the transport mechanisms of telmisartan involving transporters.

In the first part of this study, we investigated the transcellular transport properties of telmisartan using Caco-2 cells. We found that the apical-to-basal transport of telmisartan was greater than the basal-to-apical transport (Fig. 1). Thus, we focused on the uptake mechanism of telmisartan in the brush-border membrane. The uptake of telmisartan by Caco2 cells was shown to be energy- and proton-dependent (Fig. 2, Table 1).

To investigate the drug-drug interaction involving the apical-localized telmisartan transporter, the effects of various drugs that are clinically coadministrated with telmisartan on the uptake of telmisartan by Caco- 2 cells were determined. Several monocarboxylates inhibited the uptake of telmisartan, suggesting that MCTs are involved in the uptake of telmisartan (Table 2). To confirm this hypothesis, we investigated the inhibitory effect of salicylic acid derivatives on the uptake of telmisartan. Only acetylsalicylic acid, a monocar- boxylate, significantly inhibited the uptake of telmisartan (Table 2).

Hadjiagapiou et al. previously reported that five isoforms of MCTs (MCT1, MCT3, MCT4, MCT5, and MCT6) are identified in Caco-2 cells and that MCT5 and MCT6 are much less abundant compared with MCT1. ${ }^{31)}$ Moreover, $\mathrm{H}^{+}$dependent transport of monocarboxylate has been direct demonstrated for MCT1-MCT4. ${ }^{32}$ ) Next, we examined the inhibitory effects of monocarboxylates on the uptake of telmisartan in order to evaluate the contribution of MCT1MCT4 to the uptake of telmisartan. Although some of monocarboxylates, including $\mathrm{CHC}$, inhibited the uptake of telmisartan, L-lactic acid, which is a typical substrate of MCT1MCT4, ${ }^{27,28,32)}$ did not affect the uptake of telmisartan (Table 2 ). These results suggest that the contribution of MCT1MCT4 to the uptake of telmisartan is minor.

Since acetic acid is one of the simplest monocarboxylates, we investigated the inhibitory manner of acetic acid on the uptake of telmisartan. Acetic acid was found to inhibit the uptake of telmisartan competitively (Fig. 3). Moreover, preloading of acetic acid enhanced the uptake of telmisartan, showing a trans-stimulation effect (Fig. 4). These findings indicated that telmisartan shares a transporter with acetic acid. Although acetic acid is reported to be a substrate for several MCTs, the contribution of each MCT to the intestinal transport of acetic acid has not been investigated. Further studies are needed to elucidate the mechanisms of telmisartan uptake.

The absorption of drugs from the gastrointestinal tract is one of the important determinants for oral bioavailability. Since patients usually take many kinds of drugs at the same time, it is possible that drug interactions at the intestinal absorption level are caused by the inhibition of transporters in the intestine. Drug-drug interactions involving MCTs are likely to occur due to their broad substrate specificities. It is possible that telmisartan reduces the absorption of coadministered drugs by sharing the MCTs. We have to be aware of telmisartan-drug interactions involving MCTs.

In summary, we have demonstrated that the carrier-mediated transport system is involved in the uptake of telmisartan by Caco- 2 cells and that the apical-localized transport system is similar to MCTs, but not MCT1-MCT4. Since MCTs has an important role in the intestinal absorption of pharmacologically active compounds, it is important to be aware of the potential of telmisartan-drug interactions involving MCTs and to act in order to prevent undesirable and harmful clinical consequences.

\section{REFERENCES}

1) Burnier M., Brunner H. R., Lancet, 355, 637-645 (2000).

2) Wienen W., Hauel N., van Meel J. C., Narr B., Ries U., Entzeroth M., Br. J. Pharmacol., 110, 245-252 (1993).

3) Neutel J. M., Smith D. H., Adv. Ther., 15, 206-217 (1998).

4) Smith D. H., Neutel J. M., Morgenstern P., Adv. Ther., 15, 229-240 (1998).

5) Neutel J. M., Frishman W. H., Oparil S., Papademitriou V., Guthrie G., Am. J. Ther, 6, 161-166 (1999).

6) Lacourciere Y., Lenis J., Orchard R., Lewanczuk R., Houde M., Pesant Y., Wright J., Wilson T., Martin K., Blood Press Monit., 3, 295-302 (1998).

7) Freytag F., Schelling A., Meinicke T., Deichsel G., Clin. Ther, 23, $108-123(2001)$. 
8) Mallion J., Siche J., Lacourciere Y., J. Hum. Hypertens., 13, 657—664 (1999).

9) Mazzolai L., Burnier M., Drug Saf., 21, 23-33 (1999).

10) Lacourciere Y., Int. J. Clin. Pract., 53, 99-103 (1999).

11) Pylypchuk G. B., Ann. Pharmacother, 32, 1060-1066 (1998).

12) Katsura T., Inui K., Drug Metab. Pharmacokinet., 18, 1-15 (2003).

13) Tamai I., Takanaga H., Maeda H., Ogihara T., Yoneda M., Tsuji A., Pharm. Res., 12, 1727-1732 (1995)

14) Li Y. H., Ito K., Tsuda Y., Kohda R., Yamada H., Itoh T., J. Pharmacol. Exp. Ther., 290, 958-964 (1999).

15) Cavet M. E., West M., Simmons N. L., Br. J. Pharmacol., 118, 13891396 (1996).

16) Takara K., Sakaeda T., Tanigawara Y., Nishiguchi K., Ohmoto N., Horinouchi M., Komada F., Ohnishi N., Yokoyama T., Okumura K., Eur. J. Pharm. Sci., 16, 159-165 (2002).

17) Shu C., Shen H., Hopfer U., Smith D. E., Drug Metab. Dispos., 29, 1307-1315 (2001).

18) Hidalgo I. J., Raub T. J., Borchardt R. T., Gastroenterology, 96, 736749 (1989).

19) Itagaki S., Sugawara M., Kobayashi M., Miyazaki K., Iseki K., Drug Metab. Pharmacokinet., 18, 238-244 (2003).

20) Itoh T., Itagaki S., Sumi Y., Hirano T., Takemoto I., Iseki K., Cancer
Chemother: Pharmacol., 55, 420-424 (2005).

21) Itagaki S., Kobayashi Y., Otsuka Y., Kubo S., Kobayashi M., Hirano T., Iseki K., J. Agric. Food Chem., 53, 2499-2502 (2005).

22) Lowry O. H., Rosebrough N. J., Farr A. L., Randall R. J., J. Biol. Chem., 193, 265-275 (1951).

23) Terlouw S. A., Masereeuw R., van den Broek P. H., Notenboom S., Russel F. G. M., Br. J. Pharmacol., 134, 931-938 (2001).

24) Wu X., Whitfield L. R., Stewart B. H., Pharm. Res., 17, 209-215 (2000).

25) Legen I., Kristl A., Eur. J. Pharm. Biopharm., 56, 87-94 (2003)

26) Takanaga H., Tamai I., Tsuji A., J. Pharm. Pharmacol., 46, 567-570 (1994).

27) Halestrap A. P., Price N. T., Biochem. J., 343, 281-299 (1999).

28) Dimmer K. S., Friedrich B., Lang F., Deitmer J. W., Broer S., Biochem. J., 350, 219-227 (2000).

29) Mizuno N., Sugiyama Y., Drug Metab. Pharmacokinet., 17, 93-108 (2002).

30) Ayrton A., Morgan P., Xenobiotica, 31, 469-497 (2001).

31) Hadjiagapiou C., Schmidt L., Dudeja P. K., Layden T. J., Ramaswamy K., Am. J. Physiol., 279, G775-G780 (2000).

32) Enerson B. E., Drewes L. R., J. Pharm. Sci., 92, 1531-1544 (2003). 